\title{
Representaciones y estereotipos latinoamericanos en las series españolas de prime time (2014-2017)
}

Latin American representations and stereotypes in Spain prime time series (2014-2017)

Luis M. Romero-Rodríguez / luismiguel.romero@unir.net http://orcid.org/0000-0003-3924-1517 ESAI Business School, Universidad Espiritu Santo, Ecuador y Universidad Internacional de La Rioja, España

Patricia de-Casas-Moreno / patricia@grupocomunicar.com http://orcid.org/0000-0003-1205-8106 Universidad de Nebrija / Universidad de Huelva, España Pablo Maraver-López / pablo.maraver@dedu.uhu.es http://orcid.org/0000-0003-2457-0887 Universidad de Huelva, España M. Amor Pérez-Rodríguez / amor@uhu.es http://orcid.org/0000-0001-8312-5412 Universidad de Huelva, España

\begin{abstract}
The present article aims to analyze the representations and projected stereotypes of Latin American characters in Spanish fiction prime-time series (2014-2017). The study will be based on a comparison of the projected image of the Latin American countries in the three major Spanish print media and fictional elements of the actors of the series. Secondly, we will analyze the projected personality traits, based on the cognitive-behavioral theory and non-participant observation, allowing us to remove their psychological profiles. Among the main results and conclusions, it should be noted that the majority of the emerging codes are highly negative connotations, exalting the anti-stereotyping of the Latin American community in Spain.
\end{abstract}

Key words: Latin America, fiction, television, stereotypes, image.

Resumen: El presente artículo tiene como objetivo analizar las representaciones y estereotipos proyectados de personajes latinoamericanos en las series de ficción españolas de prime time (2014-2017). El estudio parte de una comparativa discursiva de la imagen proyectada de los latinoamericanos en los tres principales medios impresos españoles y los elementos ficcionales de los actores de las series. Ello se completa con el análisis de los rasgos de personalidad proyectada, basada en la teoría cognitivo-conductual y la observación no participante, permitiendo extraer sus perfiles psicológicos. Entre los principales resultados y conclusiones se destaca que la mayoría de los códigos emergentes son de connotaciones altamente negativas, exaltando los antivalores estereotipados de la comunidad latinoamericana en España.

Palabras clave: Latinoamérica, ficción, televisión, estereotipos, imagen. 


\section{Introducción $^{1}$}

Las realidades son constructos discursivos (Watzlawick, 1979; Gilovich, 1993; Searle, 1998; Berger y Luckmann, 2003; March y Prieto, 2006) y los medios de comunicación y las industrias culturales son canales de difusión masiva y engranaje socio-cognitivo para que estas realidades construidas a través del discurso sean apropiadas, socializadas e institucionalizadas en la opinión pública. Por su parte, el proceso de mediamorfosis, caracterizado por el nacimiento de nuevas plataformas de contenidos en Internet hace que los medios de comunicación convencionales sean arrastrados a una dinámica de competencia, donde imperan los contenidos de entretenimiento y pseudo-informativos (Soler, 2005; Aguaded y Romero-Rodríguez, 2015), adquiriendo así las audiencias un valor de mercado compartido por todas las entidades que participan en esta interrelación comunicativa: los medios, los anunciantes, los publicistas y los estrategas de medios (Jara y Garnica, 2007; Romero-Rodríguez et al., 2015a).

Los contenidos televisivos -especialmente los de ficción-presentan modelos de conducta, inducen valores, homogenizan los gustos, modelan las identidades e ideologías y aportan estereotipos (Gubern, 1987; Villar-Onrubia, 2005). Por supuesto, ese producto mediático no es la representación fiel de una realidad objetiva, sino una recreación propia de su proceso productivo que dependerá directamente de los intereses, posiciones ideológicas, deontológicas y epistemologías de los actores del sistema (medio/empresa, producción, guionistas, anunciantes, publicistas, entre otros) (Romero-Rodríguez et al., 2016). Estas representaciones colectivas suelen estar bajo la generalización de tópicos y estereotipos fundamentados en tomar características de segmentos societarios, cohesionados por la exaltación e incluso exageración de conductas de quien o quienes se desean representar; por lo tanto, es una práctica discursiva cosificadora que sustantiva las características de la otredad, delineando su imagen proyectada a partir de la fijación, la reiteración, la repetición y la naturalización de esos rasgos transmitidos a través del discurso (Ardevol y Muntañola, 2004).

Baudrillard (1974) se refería a los estereotipos como una "descomposición del valor del alma”, en el que se transmuta lo importante al concepto de imagen como herramienta estética, difundiéndose separaciones marcadas

1 La presente investigación está enmarcada en el Proyecto I+D “Competencias mediáticas de la ciudadanía en medios digitales emergentes (smartphones y tablets): Prácticas innovadoras y estrategias educomunicativas en contextos múltiples" con clave EDU-2015-64015-C31-R del Ministerio de Economía y Competitividad de España (MINECO/FEDER). 
sobre las diferencias humanas en razón de sexo, razas, religiones, estatus socioeconómico y origen geográfico. Aunado a esto, Sartori (1998), en la misma línea crítica, afirmaba que la televisión se ha convertido en un vehículo antropogénico que genera un nuevo tipo de ser humano, el homo videns.

El estudio de los tópicos, estereotipos e imágenes proyectadas en la televisión no resulta baladí. Según los datos del Instituto Nacional de Estadística (INE) (INE, 2016), el 96,9\% de los españoles suelen ver la televisión por una media de tres horas al día, manteniéndose como el medio de comunicación convencional más consumido en la actualidad, al menos en España. Si a esto le sumamos los servicios de video bajo demanda (VOD-PPV), time-shif, servicios de televisión a la carta, y sistemas y aplicaciones de visualización de contenido audiovisual lineal por Internet (como Yomvi, Netflix, HBO, MovistarTV, entre otros), el consumo en diferido y bajo demanda en 2015 registró un $77 \%$ de preferencia al consumo lineal (en directo) (Fundación Telefónica, 2016). Esto es indicativo de que, independientemente del soporte (televisión o Internet), el contenido televisivo impera en las ofertas de entretenimiento y en el hábito de consumo en España.

Por su parte, según las estadísticas de flujos migratorios y residencia de inmigrantes en España, recolectadas por el INE (2016a), el 11,7\% de la población española (equivalente a más de 5,5 millones de personas) es de origen extranjero, de los cuales 2.298.787 provienen de América Latina, principalmente de Ecuador (19,49\%), Colombia (14,37\%), Argentina (12,62\%), Bolivia (10,47\%), Perú (7,06\%) y Venezuela (6,29\%).

En el mismo orden de ideas, el Informe de Actitudes hacia la Inmigración 2014, del Centro de Investigaciones Sociológicas (CIS) (CIS, 2014), muestra con meridiana claridad cómo existe actualmente una actitud más desfavorable en contra de la inmigración, en comparación con la encuesta realizada en 1996, cuando la postura generalizada estaba a favor de la misma (CIS, 1996; Muñiz-Muriel et al., 2008). En este sentido, el estudio de opinión en referencia demuestra que los inmigrantes están vinculados perceptivamente con pobreza y desigualdad (13,9\%), que su número es elevado o excesivo $(71,5 \%)$, que las leyes españolas son muy o demasiado tolerantes con el ingreso de la inmigración $(59,4 \%)$ y que los inmigrantes traen a España problemas de delincuencia e inseguridad (20,8\%) (CIS, 2014).

La presente investigación examinará las representaciones, imágenes proyectadas y estereotipos de la población latinoamericana en las series españolas de horario prime time, específicamente de aquellas series de ficción que se transmitieron entre enero de 2014 y mayo de 2017, a través de los principales canales generalistas de televisión en España por share y rating de audiencia 
(cuota de pantalla), a saber: Antena 3 (18,4\%), TVE1 (12,3\%) y La Sexta $(7,9 \%)$ (AMIC, 2016). De esta forma, solo se tomarán en consideración aquellas series de horario de máxima audiencia (horario estelar o prime time), cuyas cuotas de esta hayan superado el 15\%, según los datos del "Estudio General de Medios 2015-2016”, de la Asociación para la Investigación de Medios de Comunicación (AMIC, 2016).

\section{Medios de comunicación e inmigrantes}

Los medios de comunicación se han vuelto los instrumentos de difusión más demandados por la audiencia. Para comprender e interpretar los múltiples mensajes emitidos, se debe establecer una serie de pautas para el correcto consumo. En 1955, Gregory Bateson (Hernández-Hidalgo, 2015) introduce un nuevo término conocido como framing, convirtiéndose en referencia para entender qué es la realidad y qué no lo es. Sin embargo, no es sino hasta la década de 1960 que este término se aplica al ámbito de la comunicación y comienzan a analizarse los significados de la realidad y sus repercusiones con los mass media. A partir de entonces es cuando nace la llamada "Teoría del framing", estudiando la carencia de objetividad de los medios, la forma en que estos emiten la información y los encuadres y formas de presentación de la noticia (Hernández-Hidalgo, 2015).

De este modo, son múltiples los estudios que han señalado que los medios de comunicación utilizan unos determinados encuadres en el momento de tratar al colectivo de los inmigrantes, pues fungen "como constructores de la identidad cultural y de la creación de estereotipos y mitos" (Casetti y Di-Chio, 1999: 126).

Las sociedades modernas están caracterizadas por el pluralismo cultural. La sociedad española establece relaciones formales y simbólicas entre la sociedad de recepción y los inmigrantes que se incorporan en su demografía. Según Bañón (2002: 281), existe un continuo debate social en torno a la inmigración, explicando que el debate, como hiper-género discursivo, "permite tratar adecuadamente la diversidad de actores, tipos discursivos, medios y actitudes que participan en el tema de la migración”. Por su parte, RodrigoAlsina y Gaya-Morla (2011) apuntan que la información etnocéntrica se encuentra presente en la construcción periodística y la construcción de ideas y opiniones negativas sobre un determinado grupo.

Por tanto, la población española es cada vez más heterogénea y multicultural, y los medios de comunicación se encargan de transmitirlo en sus emisiones, aun cuando la desinformación y la infoxicación de los mensajes 
ofertados por los contenidos de entretenimiento están generando un enmascaramiento de las realidades de convivencia (Torres-Toukoumidis et al., 2017). La televisión emplea constantemente estas estrategias para aprehender la realidad, provocando que el telespectador conforme su propio proceso de percepción. Sin embargo, en la ficción, la audiencia dispone de menos tiempo para reconocer e identificar las ideas emitidas, aumentando las posibilidades de establecimiento de los estereotipos (Galán-Fajardo, 2006).

Los estudios en comunicación siempre han estado interesados en analizar a los personajes de ficción y las interacciones que estos realizan dentro de sus emisiones. Así, la teoría del cultivo, la teoría de la persuasión narrativa, la teoría del entretenimiento y la del contacto intergrupal mediático son el mejor método para investigar la relación entre los medios de comunicación y las minorías étnicas (Shanahan y Morgan, 1999; Igartua, 2007; Park, 2012; Ramos et al., 2014). Las investigaciones más recientes han demostrado que la teoría del contacto intergrupal mediático ayuda y complementa las interacciones interpersonales de inmigrantes con el personaje nacional. El contacto parasocial se ha convertido en el vínculo de unión para que la sociedad conozca y se relacione con miembros de otros grupos culturales, contribuyendo este trato a la mejora de las actitudes intergrupales, reduciendo ideas y actitudes discriminatorias, que más tarde se consumen en las series de ficción televisivas (Ramos et al., 2014).

Los efectos mediáticos de construcción discursiva de estereotipos, tópicos y prejuicios han tenido un extenso abordaje en la literatura académica (Reardon, 1983; Gerbner y Gross, 1983; Seiter, 1986; Entman y Rojecki, 2000; Dixon, 2000). Asimismo, la temática ha sido abordada desde la generación de actitudes, demonización, polarización y sentimientos de temor hacia otros colectivos (Cohen, 1972; Goode y Ben-Yehuda, 1994; Pidgeon et al., 2003; Critcher, 2006; Romero-Rodríguez et al., 2015).

Por otro lado, es hasta el año 2003 cuando los inmigrantes aparecen en la ficción televisiva de producción española, ocupando siempre personajes secundarios y relacionados con estereotipos negativos y evitando la integración en la serie. La construcción de la imagen del inmigrante latinoamericano está estrechamente relacionada con la construcción simbólica de la realidad, donde el discurso de los medios de comunicación es el encargado de establecer un vínculo socio-cognitivo entre el mito y la verdad (Retis, 2004: 125).

Otros enfoques señalan que los espectadores juzgan al inmigrante según como los medios de comunicación lo representen en la pantalla; por eso hay que destacar la construcción sesgada que existe de los inmigrantes frente a los personajes nacionales en la ficción televisiva española, mostrando sendas 
características sobre ellos: 1) hay diferencias en función de las variables demográficas, como por ejemplo el nivel de estudios o la ocupación laboral, que tiende a ser precaria; 2) la configuración psicosocial indica que pueden alcanzar comportamientos violentos, victimización del personaje y eficacia cognitiva (Sanders y Ramasubramanian, 2012; Igartua et al., 2012).

Los estereotipos relacionados con los personajes latinoamericanos en series de ficción están muy arraigados en la percepción crítica del televidente. Las características asociadas a este grupo cultural son menos favorables que las relacionadas con las personas de color (Ramos, 2014). Según Rizo (2001), la inmigración en los medios se presenta de dos formas diferentes: por un lado, induciendo al temor y mostrando a la persona extranjera como un peligro para la sociedad, y por otro, exponiendo sus debilidades por la situación económica, incitando compasión sobre ellos.

Según van Dijk (1997), este colectivo está cada vez más asociado con amenazas socioeconómicas y culturales, y con la violencia. Además, expone que los medios, para lograr establecer este imaginario, realizan una serie de estrategias discursivas:

- Diferenciación entre "nosotros" y "ellos".

- Matización de los problemas que pueden causar los inmigrantes.

- Asociación de temas negativos con la inmigración (violencia, terrorismo, desintegración social, etcétera).

En la actualidad, las series de ficción televisivas incorporan personajes inmigrantes y/o extranjeros, generando ideas y estereotipos arraigados a los actores. Los personajes de origen latinoamericano están cobrando un rol notorio en los contenidos, convirtiéndose en el objeto de estudio de muchas investigaciones científicas. Los papeles relacionados llevados a cabo por este grupo son en su mayoría de background, ocupando un segundo o tercer lugar en las apariciones de las emisiones. Se caracterizan por ser personajes de baja formación académica, de bajo nivel económico y por realizar trabajos no cualificados y mal pagados. Asimismo, suelen desempeñar roles de villanos o de víctimas, mientras que los papeles neutros o protagónicos son acaparados por personajes nacionales (Ramos et al., 2014).

Por otra parte, las series de ficción se caracterizan por ser productos televisivos resultantes de un proceso en el cual intervienen múltiples factores humanos, técnicos y económicos. Al pertenecer a la industria audiovisual, deben garantizar su viabilidad comercial y fortalecer las dimensiones socioculturales de sus contenidos (Castelló-Cogollos, 2004: 46).

Para comprender los diálogos y los contenidos, debemos centrarnos en dos teorías: por un lado, en la "hipótesis de referencia" (Sperber y Wilson, 
1981), la cual consiste en aludir a una información previa a la que se ha hecho referencia, comprendiendo el mensaje por parte del receptor. Por el otro, "la hipótesis de la intencionalidad” (Clark y Gérrig, 1984), que le da importancia al papel del autor de la ironía para comprender la actitud del emisor.

Es necesario destacar que tanto el contexto situacional como las relaciones interpersonales son importantes para entender este término, apoyándonos con la "hipótesis aditiva”, según la cual la comprensión del lenguaje irónico depende del conocimiento del espectador, así como de la relación que se establece entre el autor y la víctima (Alonso y Castillo, 1991).

\section{Método}

El presente trabajo tiene como objetivo esencial determinar las representaciones, imágenes y estereotipos de los latinoamericanos en las series de ficción españolas de prime time en el periodo 2014-2017. Para ello se utilizará un enfoque cuali-cuantitativo con tres técnicas diferenciadas: 1) Comparativa cuantitativa de los estereotipos, tópicos, representaciones e imagen proyectada de los latinoamericanos en los tres principales medios impresos de España, que permitirá realizar una primera criba sobre los elementos del estudio para cotejar, mediante la observación no participante, si la representación de unidades de análisis, entendidas como los elementos en los que recae la obtención de información y que deben ser definidos con propiedad -es decir, precisar, a quién o a quiénes se va a aplicar la muestra para obtener la información (Centty, 2006) - es disímil con la que se expone en las series de ficción. 2) La segunda técnica, también cualitativa, corresponde al análisis de rasgos de personalidad proyectada, basada en la teoría cognitivoconductual con aproximación de observación no participante, mediante el modelo de los cinco factores de Costa y McCrae (1990) y McCrae y Costa (1999), lo cual permitirá en una tercera banda; 3 ) extraer el perfil psicológico, de roles y el análisis de las imágenes de los personajes emergentes.

La definición de personalidad se emplea para referirse al conjunto de pensamientos, emociones y acciones características de cada persona, quien al interactuar con el medio reacciona de forma distinta, dependiendo de la circunstancia; por lo que estas características son permanentes en el tiempo y en diferentes situaciones. El análisis de la personalidad constituye una mezcla de factores temperamentales y caracterológicos, los cuales muestran que tales características son aspectos biológicos y hereditarios, sin perder de vista la manera en que la sociedad influye dentro del comportamiento (Caballo, 2004). 
Por su parte, Fernández y Martínez (2009) sostienen que la personalidad representa todas las características del individuo que definen sus propios patrones de sentir, pensar y actuar, los cuales le permitirán adaptarse en cualquier medio que quiera desarrollarse, reflejando allí también su desenvolvimiento, formas de afrontamiento y resolución de conflictos.

El modelo de los cinco factores de la personalidad de Costa y McCrae (1990) y McCrae y Costa (1999), también conocido como "los cinco grandes" (bigfive), propone los siguientes elementos de análisis ordenados jerárquicamente:

1. Extraversión-introversión: define la preferencia de la persona para encontrarse sola o acompañada, y verifica la facilidad que posee para experimentar emociones positivas o tener entusiasmo y sus capacidades sociales.

2. Amabilidad-oposicionismo: define la interacción social y las respuestas que se ofrecen a los demás. En cuanto a la amabilidad, se indican atributos como simpatía, generosidad, fidelidad, gentileza o colaboración; mientras que en el oposicionismo hay características como: frialdad, crueldad, rigidez, ser poco amigable y desagradecida.

3. Responsabilidad-falta de responsabilidad: hace referencia al grado de organización, control, persistencia y motivación que posee la persona para alcanzar sus objetivos.

4. Estabilidad emocional-neuroticismo: refleja la vida emocional de una persona; por un lado: estabilidad, tranquilidad y poca emotividad; por otro, tendencia a la inestabilidad, miedo a la emotividad, preocupación y mal humor.

5. Apertura a la experiencia-cierre ante la experiencia: es la búsqueda de experiencias y placer por lo desconocido al momento de tenerlas. Por un lado, las personas serán originales, ingeniosas, perspicaces, imaginativas, mientras que por el otro, adoptarán características conservadoras.

Del análisis resultante se obtendrá una conclusión de cada una de las dimensiones estructuradas de la personalidad, buscando su vinculación respecto a los rasgos de representación proyectados por los medios sobre los latinoamericanos. Así, se parte de la hipótesis general (H0): la representación de los latinoamericanos en las series en estudio siguen los tópicos y perfiles estereotipados de otredades con baja formación académica, de bajo nivel socioeconómico, relacionados con actividades delictivas y/o con efectuar trabajos no cualificados, con bajos salarios y en ocasiones de forma ilegal. Asimismo, se plantea que ( $\mathrm{H} 1)$ no hay ningún latinoamericano en roles protagónicos o papeles neutros; por lo tanto, suelen desempeñar roles 
Luis M. Romero-Rodríguez, Patricia de-Casas-Moreno, Pablo Maraver-López y M. Amor Pérez-Rodríguez. Representaciones y estereotipos latinoamericanos en las series españolas de prime time (2014-2017)

de villanos o víctimas, sin que su papel juegue un factor determinante en el curso de la narrativa.

\section{Estrategias metodológicas y muestra}

Para cumplir el primer objetivo específico de la presente investigación, se realizó el análisis semántico de un total de 232.382 unidades de análisis de los tres principales medios impresos generalistas españoles por número de lectores, según el "Estudio General de Medios 2015-2016" (AMIC, 2016). Esto se llevó a cabo con el fin de establecer una base comparativa de los estereotipos y tópicos perceptivos relacionados con la sociedad latinoamericana en la sociedad española y los personajes de las series de ficción emitidos a través de la televisión. Para esta primera criba se utilizó un sistema de búsqueda bajo los algoritmos booleanos por temática y se obtuvieron los resultados que se pueden apreciar en la Tabla $1 .^{2}$

Para la precisión de la muestra de la segunda fase del estudio, correspondiente a la presencia de personajes latinoamericanos en series de ficción españolas, se partió de una criba seleccionando aquellas series de ficción en horario prime time, transmitidas entre 2014 y 2017, en las que hubiera personajes principales y/o secundarios, cuya representación ficcional fuera un personaje latinoamericano. A partir de los datos de audiencia recogidos por FórmulaTV (2017) y triangulados por la Oficina de Justificación de la Difusión (OJD), se precisó el promedio de rating anual promedio -cuota de pantalla o share de audiencia-, con lo cual se obtuvieron los resultados que se muestran en la Tabla 2.

Como se puede observar meridianamente en la Tabla 2, hay en la criba programas que se estrenaron en 2015 (Olmos y Robles, Vis a Vis, Rabia), otros que se estrenaron en 2016 (La Embajada), series que no han continuado o que no han iniciado su segunda temporada (Olmos y Robles, Rabia) o series cuya última emisión fue en 2014 (Aida). Con el fin de obtener el share total, se dividió su rating total anual entre tres, independientemente de sus emisiones y contabilizaciones anuales.

Para realizar la criba específica de los personajes y determinar la muestra de estudio, tomaremos en consideración las series de ficción que sobrepasen el $10 \%$ de la cuota de pantalla en el share total o que, sin tener emisiones durante los tres años de estudio, alcancen al menos $10 \%$ del share en cualquiera de sus años. De esta manera, la muestra efectiva queda configurada de la si-

2 Todas las tablas se encuentran en el Anexo, al final del presente artículo (Nota del editor). 
guiente manera: (m1) Águila Roja, (m2) Olmosy Robles, (m3) Vis a Vis, (m4) La Embajada, (m5) La que se avecina, (m6) Aida.

$\mathrm{Al}$ no haber evidencias de representación de personajes latinoamericanos en las series Águila Roja (m1) y Olmos y Robles (m2) -ambas de la cadena de televisión pública Radio Televisión Española (RTVE)-, se exceptúan las unidades del análisis posterior, quedando la muestra efectiva $(\mathrm{Me})$ conformada por las series: Vis a Vis, La Embajada, La que se avecina y Aida (véase Tabla 3).

\section{Resultados}

Tal como se mencionó en el apartado de metodología del presente estudio, los resultados se presentan en tres etapas para cumplir los objetivos de la investigación. En una primera fase se realizó la comparación entre los tópicos y número de representaciones de los inmigrantes latinoamericanos en los principales medios impresos españoles, respecto a los personajes latinoamericanos de las series de ficción españolas, determinados como muestra efectiva.

En la segunda etapa se analizaron los rasgos de personalidad proyectada, utilizando la teoría cognitivo-conductual con aproximación de observación no participante, mediante el modelo de los cinco factores de Costa y McCrae (1990) y McCrae y Costa (1999), finalizando con la extracción del perfil psicológico, de roles y el análisis de las imágenes de los personajes emergentes.

\section{Comparativa de estereotipos y representaciones}

De la extracción de las unidades de análisis con algoritmos booleanos de los tres principales medios impresos generalistas españoles por número de lectores, según el "Estudio General de Medios 2015-2016" (AMIC, 2016), emergieron con alta frecuencia $(f>=1162 n) 26$ códigos, de los cuales: dos presentan connotación positivā (gastronomía y felicidad/humor) representando un $8 \%$; dos, connotación neutra (religión e inmigración) con un 9\%; y los 22 restantes, connotaciones negativas/altamente negativas (pobreza, dictadura, agresiones, enfermedades, populismo, delincuencia, homosexualidad, robos, homicidios, precariedad, prostitución, inmigración ilegal, crímenes, narcotráfico, mafias, machismo, drogas, trabajo ilegal, alcoholismo, violencia, inmigración, analfabetismo, pandillas) con un $83 \%$ (véase Tabla 4).

Mediante la observación no participante y utilizando una validación interjueces, se comparó cuáles de los códigos emergentes del análisis ut supra 
referenciado está asociado directamente con los personajes objeto del presente estudio (véase Tabla 5). A los personajes con códigos emergentes de connotación positiva les serán asignados el valor +1 por cada elemento, mientras que los códigos de connotación neutra serán evaluados con $0 \mathrm{y}$ negativa con -1 .

Por lo tanto, tras analizar cada uno de los personajes seleccionados, se puede destacar que las connotaciones negativas imperan frente a las positivas. El código positivo de "felicidad/humor" es el único que se repite en cada personaje; mientras que en relación con los códigos negativos, los más reiterativos son "delincuencia”, "inmigración”, "trabajo ilegal” y "pobreza”. Los personajes que han alcanzado el valor más bajo son: Carlos (Argentina) y Machu Pichu (Ecuador), con una puntuación de -1. A pesar de ser inmigrantes y extranjeros, son aceptados según sus rasgos y características, y se presentan alejados de los estereotipos arraigados a los latinoamericanos.

Sin embargo, aquellos personajes que han obtenido puntuaciones más elevadas son: Jocelyn (Colombia) y Parrales (Colombia), con valores de -6 y -7. Sin duda, estas figuras están tildadas por todas aquellas connotaciones negativas que caracterizan a los latinoamericanos en los estudios de estereotipos en la actualidad. Los rasgos de inmigración, violencia, precariedad, pobreza, narcotráfico, entre otros, favorecen la concepción de ideas negativas sobre los diferentes grupos sociales.

\section{Rasgos de personalidad}

El estudio de los rasgos de la personalidad ayuda a conocer el conjunto de pensamientos, emociones y acciones que caracterizan a la muestra del presente estudio. La personalidad se convierte en el objeto principal de evaluación, basado en la teoría cognitiva-conductual de los cinco rasgos factores de la personalidad, que se detalla a continuación. Asimismo, los datos arrojados son resultado de una validación de interjueces.

La primera dimensión de este análisis es la "extraversión/introversión”. Se puede observar con un alto grado de acuerdo (prom. $k=0.864$ ) que el rasgo característico e imperante en los personajes latinoamericanos es el de ser personas introvertidas con dificultad para ser aceptadas por la sociedad, a causa de los estereotipos previos creados sobre su procedencia. En esta dimensión se ha alcanzado un $100 \%$ de acuerdo en la evaluación interjueces $(k=1.00)$, mientras que en los personajes de Sole (Cuba) y Carlos (Argentina) se encuentra un $66.66 \%$ de acuerdo $(k=0.66)$ (véase Tabla 6$)$. 
En segundo lugar, los porcentajes de acuerdo interjueces para cada personaje según el rasgo de personalidad "amabilidad/oposicionismo" se mantienen en conformidad para todos los personajes seleccionados $(k=1.00)$, imperando la característica de amabilidad entre ellos. Este tipo de personajes tienden a demostrar una faceta afable, con el fin de ser aceptados en un grupo social (véase Tabla 7 ).

Por su parte, en la dimensión "responsabilidad/falta de responsabilidad" hay un $100 \%$ de acuerdo para los personajes analizados $(k=1.00)$, salvo para el de Carlos (Argentina), cuyo porcentaje de acuerdo es de $66.66 \%$. Las figuras evaluadas presentan mayormente un alto grado de responsabilidad, debido a las connotaciones negativas que recaen sobre ellas (véase Tabla 8).

En relación con la dimensión "estabilidad emocional/neuroticismo", el grado de acuerdo alcanzado es del $100 \%$ con todos los personajes, excepto con el de Machu Pichu (Ecuador), con 66.66\%. El rasgo de neuroticismo impera frente a la estabilidad emocional en el sentido de que el personaje se encuentra fuera de su entorno de confort, lejos de su país y núcleo familiar, teniendo que aprender nuevas costumbres y las normas sociales de otro país (véase Tabla 9).

Por último, respecto a la categoría "apertura a la experiencia/cierre ante la experiencia”, los personajes han conseguido el $100 \%$ de acuerdo interjueces, excepto el 66.66\%, reflejado en los personajes de Machu Pichu (Ecuador) y Sole (Cuba). La característica de "apertura a la experiencia" ha conseguido el mayor grado de persistencia en las figuras analizadas. En este sentido, hay que destacar el esfuerzo que demuestran por pertenecer a una nueva sociedad y la esperanza de ser aceptados (véase Tabla 10).

Los personajes con un perfil psicológico más marcado son: Parrales y Joselyn (La que se avecina), al mantener un $100 \%$ de acuerdo interjueces $(k=$ $1.00)$ en los cinco grandes rasgos de personalidad.

\section{Discusión y conclusiones}

El estudio de los estereotipos y los tópicos se ha convertido en un tema de gran interés para la comunidad científica. La conformación de ideas y hábitos relacionados con el consumo de la información alejada de la realidad ha repercutido por mucho tiempo en la sociedad actual. La colectividad latinoamericana, objeto de estudio de esta investigación, se ha transformado en el punto de mira de la conformación de dichos estereotipos. Por lo tanto, la importancia de este análisis radica en las múltiples representaciones encontradas en la ficción, sobre todo la televisiva. 
Según Choi (2007), los hispanos están destinados a ser objeto de prejuicios; mientras que van Dijk (1996) señala el desconocimiento controlado en relación con los grupos marginales, favoreciendo el desarrollo de mitos. Asimismo, subraya que estas minorías étnicas son conocidas por sus problemáticas de: inmigración, empleo o educación. Sin duda, uno de los principales estereotipos que recae sobre los latinoamericanos es la homogeneización de etnia, cultura e idiosincrasia, rechazando las ideas de plurietnia y multiculturalidad existentes en el territorio español.

La televisión se ha erigido como el medio de comunicación de masas por excelencia, siendo las series de entretenimiento los contenidos más solicitados y consumidos por la audiencia. Las series de ficción televisivas españolas han propiciado el desarrollo e instauración de ideas preconcebidas sobre los personajes latinoamericanos representados. Además, cabe destacar que este colectivo está caracterizado por ser un grupo homogéneo, sin establecerse diferencias significativas sobre la procedencia norte-sur del país de América Latina (Ramos et al., 2014). La construcción de la realidad a través de los formatos audiovisuales es un tema de referencia que debe ser estudiado. Los contenidos televisivos -especialmente los de ficciónpresentan modelos de conducta, inducen valores, homogenizan los gustos, modelan las identidades e ideologías, y aportan estereotipos (Gubern, 1987; Villar-Onrubia, 2005). En definitiva, los efectos mediáticos ocasionados por la conformación de mitos, estereotipos y prejuicios desarrollan ideas erróneas sobre el colectivo estudiado.

En relación con los resultados hallados en esta investigación, se puede destacar que, al examinar las unidades de análisis de los tres principales medios impresos españoles, inciden con connotaciones positivas los códigos emergentes de "gastronomía" y "felicidad/humor" y con connotaciones neutras: "religión" e "inmigración". Por su parte, el resto de códigos emergentes, un total de 22, son señalados con connotaciones altamente negativas. El mundo latinoamericano está vinculado con ideas como: violencia, narcotráfico, asesinatos, etcétera.

Sin duda, los medios de comunicación se han convertido en el modelo informativo más aceptado por la sociedad, constituyéndose la información, como una realidad inquebrantable a pesar de la fiabilidad de sus fuentes. De esta forma, la transmisión de los múltiples rasgos estereotipados ayuda a reforzar las ideas ya existentes en la audiencia sobre estos personajes. La representación mediática juega un papel fuerte en los roles de estas figuras, mediante el uso de los rasgos físicos y actitudinales a nivel teórico (MuñizMuriel et al., 2014). 
La comparativa establecida entre los estereotipos y representaciones de los personajes nos muestra que dos de las cinco figuras han recibido connotaciones negativas muy elevadas (Jocelyn: -6 y Parrales: -7 ). Este resultado deja en evidencia que, alrededor de los personajes latinoamericanos siguen imperando fuertes prejuicios y estereotipos. Por su parte, aquellos que han obtenido un valor menos elevado han sido Carlos (-1) y Machu Pichu (-1), personajes aceptados por la sociedad. En la misma línea, la teoría cognitivaconductual cobra un papel notorio en la evaluación de los personajes, certificando los datos extraídos a través de la validación interjueces.

En consecuencia, la muestra de estudio presenta, a rasgos generales, las siguientes características personales: introvertidos, amables, con un alto grado de responsabilidad, neuróticos y abiertos a la experiencia. En suma, los grados de acuerdo en el análisis han oscilado entre $66.66 \%(\mathrm{k}=0.66)$ y $100 \%$ $(\mathrm{k}=1.00)$, estableciéndose diferencias medianamente significativas en los resultados obtenidos. En relación con el rasgo de "extraversión/introversión", los únicos sujetos que han obtenido un $66.66 \%$ de acuerdo han sido Sole (Cuba) y Carlos (Argentina). En cuanto a la "amabilidad/oposicionismo", los porcentajes de acuerdo se mantienen en conformidad con un $100 \%$. Respecto a la "responsabilidad/falta de responsabilidad", el único dato diferenciable recae sobre el personaje de Carlos (Argentina) con un 66.66\%.

Por otra parte, el rasgo de "estabilidad emocional/neuroticismo" muestra valores entre el $66.66 \%$ y el $100 \%$ en los datos obtenidos, siendo el personaje de Machu Pichu (Ecuador) el que presenta estas diferencias en el acuerdo interjueces. Por último, en lo concerniente al rasgo de "apertura a la experien$\mathrm{cia} /$ cierre ante la experiencia”, se han hallado en dos de los personajes una varianza: Machu Pichu (Ecuador) y Sole (Cuba), con el 66.66\% de pertinencia.

Globalmente, cabe destacar que, según los datos, los personajes de origen latinoamericano seleccionados en las series de ficción española se caracterizan por ser personas introvertidas y con dificultad para su aceptación en la sociedad. Asimismo, tienden a ser amables y responsables con el objeto de insertarse en un grupo social y ser aceptados con su condición de inmigrantes. Así pues, el rasgo de "neuroticismo" impera frente a la estabilidad emocional de los personajes, dado que son personas fuera de su entorno, lejos de su familia y de lo que conocen, que se ven en la obligación de empezar desde cero en un mundo con muchas diferencias sociales. De esta manera, tienden a aceptar y abrirse frente a los retos y experiencias, esperando ser admitidos por el nuevo colectivo o país.

Para concluir, hay que apuntar la necesidad de alfabetizar mediáticamente a los consumidores audiovisuales, sobre todo en cuanto a la conformación de mitos, estereotipos, hábitos y prejuicios sobre otros grupos o colectivos 
extranjeros. Los personajes latinoamericanos en los últimos años han cobrado un rol destacado en los formatos audiovisuales, ya que las series españolas tienden a incluirlos en sus contenidos con más frecuencia. La representación de las múltiples etnias y diferencias preestablecidas demuestra la multiculturalidad social que existe en un mismo entorno.

En definitiva, la presente investigación evidencia ciertas limitaciones que refuerzan la necesidad de establecer nuevas vías de estudio sobre el tema. La influencia de la televisión ha propiciado la contribución y aumento de los estereotipos: manteniéndolos o transmitiendo otros nuevos.

\section{Agradecimientos / financiación}

Este trabajo se ha elaborado en el marco de Alfamed (Red Interuniversitaria Euroamericana de Investigación en Competencias Mediáticas para la Ciudadanía), con el apoyo del Proyecto I+D+I Coordinado "Competencias mediáticas de la ciudadanía en medios digitales emergentes (smartphones y tablets): Prácticas innovadoras y estrategias educomunicativas en contextos múltiples" (EDU2015-64015-C3-1-R) (MINECO/FEDER), y de la "Red de Educación Mediática" del Programa Estatal de Investigación Científica-Técnica de Excelencia, Subprograma Estatal de Generación de Conocimiento (EDU2016-81772-REDT), financiados por el Fondo Europeo de Desarrollo Regional (FEDER) y el Ministerio de Economía y Competitividad de España.

\section{Referencias}

Aguaded, Ignacio y Romero-Rodríguez, Luis Miguel (2015), “Mediamorfosis y desinformación en la infoesfera: Alfabetización mediática, digital e informacional ante los cambios de hábitos de consumo informativo", en Education in the Knowledge Society (EKS), vol. 16, núm. 1, España: Universidad de Salamanca. Doi: http://dx.doi. org/10.14201/eks20151614457 [24 de octubre de 2017].

Alonso, María Luisa y Castillo, María Dolores (1991), "Detectando la ironía: la hipótesis aditiva como alternativa a las de referencia y la intención”, en Cognitiva, núm. 3, España: Fundación Infancia y Aprendizaje.

Rodrigo-Alsina, M. y Gaya-Morla, C. (2011), "Medios de comunicación e interculturalidad”, en Cuadernos.Info, núm. 14, Chile: Pontificia Universidad Católica de Chile. Doi: https://doi.org/10.7764/cdi.14.186

Ardevol, Elisenda y Muntañola, Nora (2004), Representación y cultura audiovisual en la sociedad contemporánea, España: Universitat Oberta de Catalunya.

AMIC (Asociación para la Investigación de Medios de Comunicación) (2016), "Estudio General de Medios 2015-2016”. Disponible en: http://www.aimc.es/-Datos-EGMResumen-General-.html [18 de mayo de 2016]. 
Convergencia Revista de Ciencias Sociales, núm. 78, 2018, Universidad Autónoma del Estado de México

Bañón, Antonio (2002), Discurso e inmigración. Propuestas para el análisis de un debate social, España: Editum.

Baudrillard, Jean (1974), La sociedad del consumo: sus mitos, sus estructuras, España: Plaza y Janés.

Berger, Peter y Luckmann, Thomas (2003), La construcción social de la realidad, Argentina: Amorrortu.

Caballo, Vicente (2004), Manual de trastornos de la personalidad: descripción, evaluación y tratamiento, España: Síntesis.

Casetti, Francesco y Di Chio, Federico (1999), Análisis de la televisión. Instrumentos, métodos y prácticas de investigación, España: Paidós.

Castelló-Cogollos, Enric (2004), "Mecanismos de construcción de la identidad cultural en las series de ficción: el caso de la televisión autonómica en España”, en Estudios sobre las Culturas Contemporáneas, núm. 10, México: Universidad de Colima.

Centty, Deymor (2006), Manual metodológico para el investigador cientifico, Perú: UNSAFacultad de Economía.

Choi, Myung (2007), "El cine y la identidad latinoamericana. Prejuicios y alienaciones", en Espéculo, núm. 37, España: Universidad Complutense.

CIS (1996), "Actitudes hacia la inmigración (estudio núm. 2214)”, Madrid: Centro de Investigaciones Sociológicas. Disponible en: http://www.cis.es/cis/opencm/ES/1_ encuestas/estudios/ver.jsp? estudio=1204 [19 de mayo de 2016].

CIS (2014), "Actitudes hacia la inmigración VII (estudio núm. 3019)”, España: Centro de Investigaciones Sociológicas. Disponible en: http://www.cis.es/cis/opencm/ES/1_ encuestas/estudios/ver.jsp? estudio=1204 [19 de mayo de 2016].

Clark, Herbert y Gérrig, Richard (1984), “On the Pretense Theory of Irony”, en Journal of experimental Psychology, núm. 113, Washington: American Psychological Association. Doi: http://dx.doi.org/10.1037/0096-3445.113.1.121 [12 de noviembre de 2017].

Cohen, Stanley (1972), Folk Devils and Moral Panics: The Creation of the Mods and the Rockers, Inglaterra: MacGibbon and Kee.

Costa, Paul y McCrae, Robert (1990), "Personality Disorders and The Five-Factor Model of Personality”, en Journal of Personality Disorders, vol. 4, núm. 4, Estados Unidos: University of Minnesota. Doi: https://doi.org/10.1521/pedi.1990.4.4.362 [10 de diciembre de 2017].

Critcher, Chas (2006), Critical Readings: Moral Panics and the Media, Inglaterra: Open University Press.

Dixon, Travis (2000), "A social cognitive approach to studying racial stereotyping in the mass media”, en African American Research Perspectives, vol. 6, núm. 1, Estados Unidos: University of Michigan.

Entman, Robert y Rojecki, Andrew (2000), The Black Image in the White Race in America, Estados Unidos: The University of Chicago Press.

Fernández-Martínez, María Elena (2009), "Estrés percibido, estrategias de afrontamiento y sentido de coherencia en estudiantes de enfermería, asociación con la salud psicológica y estabilidad emocional" [tesis doctoral], España: Universidad de León. Disponible en: https://buleria.unileon.es/bitstream/handle/10612/902/2009FERN\%C3\%81N DEZ\%20MART\%C3\%8DNEZ,\%20MAR\%C3\%8DA\%20ELENA.pdf ?sequence [30 de junio de 2017].

Fórmula TV (2017), "Relación de series. Rating”. Disponible en: http://www.formulatv. com/audiencias/ [08 de diciembre de 2017]. 
Luis M. Romero-Rodríguez, Patricia de-Casas-Moreno, Pablo Maraver-López y M. Amor Pérez-Rodríguez. Representaciones y estereotipos latinoamericanos en las series españolas de prime time (2014-2017)

Fundación Telefónica (2016), La Sociedad de la Información en España 2015, España: Ariel. Galán-Fajardo, Elena (2006), "La representación de los inmigrantes en la ficción televisiva en España. Propuesta para un análisis de contenido. El Comisario y Hospital Central”, en Revista Latina de Comunicación Social, núm. 61, España: Universidad La Laguna. Disponible en: http://www.ull.es/publicaciones/latina/200608galan.htm [2 de septiembre de 2017].

Gerbner, George y Gross, Larry (1983), "El mundo del teleadicto”, en Verón, Eliseo [comps.], La ventana electrónica: TV y comunicación, México: Ediciones Eufesa.

Gilovich, Thomas (1993), How We Know What Isn t So, Estados Unidos: The Free Press.

Goode, Erich y Ben-Yehuda, Nachaman (1994), Moral Panics: The Social Construction of Deviance, Inglaterra: Blackwell.

Gubern, Román (1987), La mirada opulenta. Exploración de la iconosfera contemporánea, España: Gili Gaya.

Hernández-Hidalgo, Inés (2015), “Medios de comunicación e inmigración: prejuicios y estereotipos. Claves para la intervención socioeducativa” (Tesis Fin de Máster), España: Universidad País Vasco. Disponible en: https://addi.ehu.es/handle/10810/14079 [17 de julio de 2016].

Igartua, Juan José (2007), Persuasión narrativa: Club Universitario.

Igartua, Juan José et al. (2012), "Analysis of immigration image in the prime time television fiction”, en Comunicación y Sociedad, núm. 25, España: Universidad de Navarra.

INE (Instituto Nacional de Estadística) (2016), "Base Medios de Comunicación 2010-2011: Televisión, TablaPx”. Disponible en: http://goo.gl/zUGRCV [07 de mayo de 2016].

INE (Instituto Nacional de Estadística) (2016a), "Base Flujos migratorios exteriores 20102011 (actualización 2013)”. Disponible en: http://goo.gl/8aHtFk [08 de mayo de 2016].

Jara, Rubén y Garnica, Alejandro (2007), ¿Cómo la ves? La televisión mexicana y su público, México: Ibope.

March, Joan Carles y Prieto, María Ángeles (2006), Análisis de la televisión en la "Generación $T V^{\prime \prime}$, España: Red Comunicar.

McCrae, Robert y Costa, Paul (1999), "A five-factor theory of personality", en Handbook of personality: Theory and research, núm. 2, Estados Unidos: The Guildfor Press.

Muñiz-Muriel et al. (2008), "El tratamiento informativo de la inmigración en los medios españoles. Un estudio comparativo de la prensa y la televisión”, en Perspectivas de la comunicación, vol. 1, núm. 1, Chile: Universidad de la Frontera.

Muñiz-Muriel, Carlos et al. (2014), “¿Retratando la realidad? Análisis de los estereotipos de los indígenas presentes en los programas de ficción de la televisión mexicana”, en Palabra Clave, vol. 17, núm. 2, Colombia: Universidad de la Sabana.

Park, Sung Yeon (2012), "Mediated intergroup contact: concept explication, synthesis, and application”, en Mass Communication \& Society, núm. 15, Inglaterra: Taylor \& Francis.

Pidgeon, Nick et al. (2003), The Social Amplification of Risk, Inglaterra: Cambridge University Press.

Ramos, María Marcos (2014), "Principales estudios realizados sobre la representación de las minorías en la ficción televisiva”, en Chasqui. Revista Latinoamericana de Comunicación, núm. 126, Ecuador: Ciespal. Doi: http://dx.doi.org/10.16921/chasqui.v0i126.268 [10 de noviembre de 2017].

Ramos, María Marcos et al. (2014), "La representación de los personajes inmigrantes en los programas de ficción”, en Vivat Academia, núm. 127, España: Universidad Complutense. Doi: http://dx.doi.org/10.15178/va.2014.127.43-71 [24 de noviembre de 2017]. 
Ramos, María Marcos e Igartua-Perosanz, Juan José (2014), “Análisis de las interacciones entre personajes inmigrantes/extranjeros y nacionales/autóctonos en la ficción televisiva española”, en Disertaciones: Anuario electrónico de estudios en Comunicación Social, núm. 7, Colombia: Universidad del Rosario.

Reardon, Kathleen (1983), La persuasión en la comunicación, España: Paidós.

Retis, Jessica (2004), "La imagen del otro: inmigrantes latinoamericanos en la prensa nacional española”, en Sphera Pública, núm. 4, España: Universidad Católica San Antonio de Murcia.

Rizo, Marta (2001), "Miedo y compasión: dos estrategias de movilización afectiva en el discurso informativo sobre el inmigrante”, en Comunica, núm. 2, Colombia: Universidad Pedagógica y Tecnológica de Colombia.

Romero-Rodríguez, Luis Miguel et al. (2015), "De la demonización a la polarización: un análisis desde el discurso digital del gobierno y la oposición venezolana”, en Argos, vol. 32, núm. 62, Venezuela: Universidad Simón Bolivar.

Romero-Rodríguez, Luis Miguel et al. (2015a), "Estereotipos, tópicos y lenguaje de la programación sensacionalista en la televisión: Programa 'Corazón’ de TVE”, en Alteridad. Revista de Educación, vol. 10, núm. 1, Ecuador: Universidad Politécnica Salesiana. Doi: http://dx.doi.org/10.17163/alt.v10n1.2015.03 [10 de noviembre de 2017].

Romero-Rodríguez, Luis Miguel et al. (2016), "Dimensions and Indicators of the Information Quality in Digital Media”, en Comunicar, vol. 24, núm. 49, España: Grupo Comunicar. Doi: https://doi.org/10.3916/C49-2016-09 [11 de noviembre de 2017].

Sanders, Meghan y Ramasubramanian, Srividya (2012), "Stereotype content and the African American viewer: An examination of African-Americans' stereotyped perceptions of fictional media characters", en Howard Journal of Communication, núm. 23, Inglaterra: Taylor \& Francis. Doi: https://doi.org/10.1080/10646175.2012.641869 [20 de octubre de 2017].

Sartori, Giovanni (1998), Homo Videns: La Sociedad Teledirigida, España: Taurus. Doi: http://dx.doi.org/10.5354/0717-9162.2003.10669 [22 de noviembre de 2017].

Searle, John (1998), La construcción de la realidad social, España: Paidós.

Seiter, Ellen (1986), "Stereotypes and the media: a re-evaluation”, en Journal of Communication, vol. 36, núm. 4, Estados Unidos: American Psychological Association. Doi: http:// dx.doi.org/10.1111/j.1460-2466.1986.tb01420.x [18 de noviembre de 2017].

Shanahan, James y Morgan, Michael (1999), Television and its viewers. Cultivation theory and research, Inglaterra: Cambridge University Press.

Soler, María (2005), "El Informe del 'Comité de sabios': bases para una televisión de calidad”, en Comunicar, núm. 25, España: Grupo Comunicar.

Sperber, Dan y Wilson, Deirdre (1981), "Irony and the use-mention distinction", en Philosophy, núm. 3, Inglaterra: University College of London.

Torres-Toukoumidis et al. (2017), "Construction of War Discourse on International News Agencies: Case Study Terrorist attacks November 13th 2015”, en Mediterranean Journal of Communication, vol. 8, núm. 1, España: Universidad de Alicante. Doi: https://www.doi.org/10.14198/MEDCOM2017.8.1.9 [11 de octubre de 2017].

van Dijk, Teun (1996), "Opiniones e ideologías en la prensa", en Comunicación y estudios universitarios, núm. 10, España: Fundación Universitaria San Pablo CEU.

van Dijk, Teun (1997), Racismo y análisis critico de los medios, España: Paidós.

Villar-Onrubia, Daniel (2005), "Hacia una televisión pública 2.0. El Creative Archive de la BBC”, en Comunicar, vol. 25, núm. 2, España: Grupo Comunicar.

Watzlawick, Paul (1979), ¿Es real la realidad? Confusión, desinformación, comunicación, España: Herder. 
Luis M. Romero-Rodríguez, Patricia de-Casas-Moreno, Pablo Maraver-López y M. Amor Pérez-Rodríguez. Representaciones y estereotipos latinoamericanos en las series españolas de prime time (2014-2017)

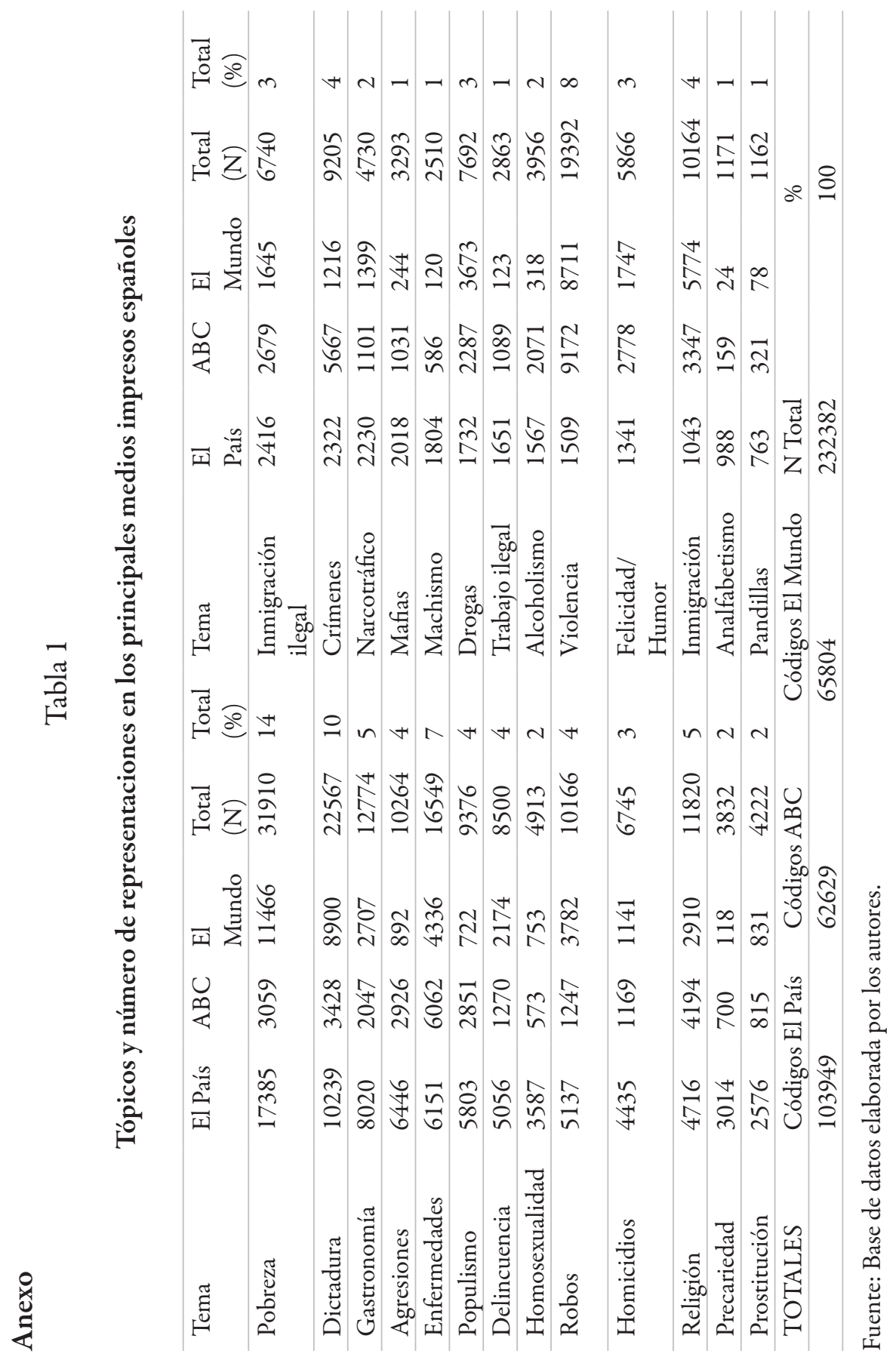




\section{Tabla 2}

Series de ficción españolas en horario prime time 2014-2016 con presencia de personajes latinoamericanos

\begin{tabular}{llllll}
\hline Emisora & Serie & $\begin{array}{l}\text { Share } \\
2014\end{array}$ & $\begin{array}{l}\text { Share } \\
2015\end{array}$ & $\begin{array}{l}\text { Share } \\
2016\end{array}$ & $\begin{array}{l}\text { Total } \\
\text { Share }\end{array}$ \\
\hline $\begin{array}{l}\text { Televisión Española } \\
\text { (La 1) }\end{array}$ & Águila Roja & $20,97 \%$ & $12,62 \%$ & $12,75 \%$ & $15,44 \%$ \\
\cline { 2 - 6 } & Olmos y Robles & --- & $14,44 \%$ & --- & $4,81 \%$ \\
\hline Antena 3 & Vis a Vis & --- & $14,48 \%$ & $20,02 \%$ & $11,62 \%$ \\
\cline { 2 - 6 } & La Embajada & --- & --- & $16,81 \%$ & $5,60 \%$ \\
\hline Cuatro & Gym Tonic & $4,58 \%$ & $5,91 \%$ & $4,77 \%$ & $5,35 \%$ \\
\cline { 2 - 6 } & Rabia & --- & $7,46 \%$ & --- & $2,48 \%$ \\
\hline Telecinco & La que se avecina & $22,32 \%$ & $23,47 \%$ & $25,45 \%$ & $22,91 \%$ \\
\cline { 2 - 6 } & Aída & $13,26 \%$ & --- & -- & $4,42 \%$ \\
\hline Share acumulado & & & & & $72,63 \%$
\end{tabular}

Fuente: Base de datos elaborada por los autores, con datos de FórmulaTV y OJD. 
Luis M. Romero-Rodríguez, Patricia de-Casas-Moreno, Pablo Maraver-López y M. Amor Pérez-Rodríguez. Representaciones y estereotipos latinoamericanos en las series españolas de prime time (2014-2017)

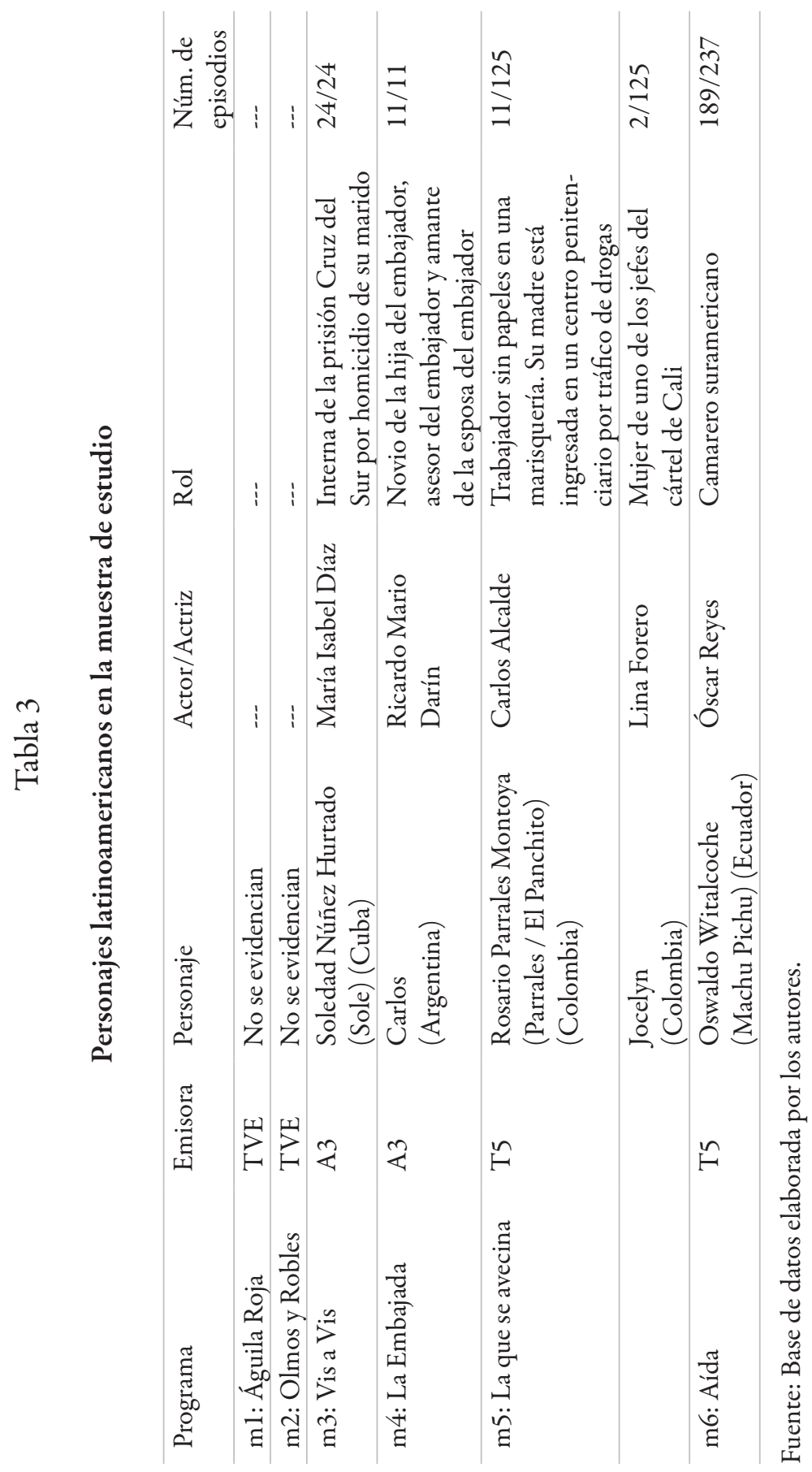




\section{Tabla 4}

Familia de códigos emergentes por connotación

\begin{tabular}{llll}
\hline Connotación & Códigos emergentes & SUM Frecuencia & $\begin{array}{l}\text { SUM \% } \\
\text { muestra }\end{array}$ \\
\hline Positiva & Gastronomía, felicidad/humor & 18640 & $8 \%$ \\
\hline Neutra & Religión, inmigración & 21994 & $9 \%$ \\
\hline Negativa & $\begin{array}{l}\text { Pobreza, dictadura, agresiones, } \\
\text { enfermedades, populismo, } \\
\text { delincuencia, homosexualidad, } \\
\text { robos, homicidios, precariedad, } \\
\text { prostitución, inmigración ilegal, } \\
\text { crímenes, narcotráfico, mafias, } \\
\text { machismo, drogas, trabajo ilegal, } \\
\text { alcoholismo, violencia, inmigra- } \\
\text { ción, analfabetismo, pandillas }\end{array}$ & $83 \%$ \\
\hline
\end{tabular}

Fuente: Elaborada por los autores. 
Luis M. Romero-Rodríguez, Patricia de-Casas-Moreno, Pablo Maraver-López y M. Amor Pérez-Rodríguez. Representaciones y estereotipos latinoamericanos en las series españolas de prime time (2014-2017)

\section{Tabla 5}

Comparativa de perfil de los personajes con los códigos emergentes

\begin{tabular}{|c|c|c|c|}
\hline Serie & Personaje & Códigos emergentes & Valor \\
\hline $\mathrm{m} 3$. Vis a Vis & $\begin{array}{l}\text { Soledad Nuñez } \\
\text { Hurtado (Sole) }\end{array}$ & $\begin{array}{l}\text { Felicidad/humor }(+1) \text {, } \\
\text { agresiones }(-1) \text {, } \\
\text { enfermedades }(-1) \text {, } \\
\text { delincuencia }(-1) \text {, } \\
\text { homicidios }(-1) \text {, } \\
\text { crímenes }(-1) \text {, } \\
\text { violencia }(-1) \text {, } \\
\text { inmigración }(0)\end{array}$ & -5 \\
\hline m4. La Embajada & Carlos & $\begin{array}{l}\text { Felicidad/humor }(+1) \text {, } \\
\text { populismo }(-1), \\
\text { machismo }(-1)\end{array}$ & -1 \\
\hline m5. La que se avecina & $\begin{array}{l}\text { Rosario Parrales } \\
\text { Montoya (Parrales) }\end{array}$ & $\begin{array}{l}\text { Felicidad/humor }(+1) \text {, } \\
\text { inmigración }(0), \\
\text { pobreza }(-1) \text {, } \\
\text { delincuencia }(-1) \text {, } \\
\text { homosexualidad }(-1) \text {, } \\
\text { precariedad }(-1) \text {, } \\
\text { narcotráfico }(-1) \text {, } \\
\text { drogas }(-1) \text {, } \\
\text { trabajo ilegal }(-1) \text {, } \\
\text { analfabetismo }(-1)\end{array}$ & -7 \\
\hline m5. La que se avecina & Jocelyn & $\begin{array}{l}\text { Inmigración }(0) \text {, } \\
\text { delincuencia }(-1) \text {, } \\
\text { robos }(-1) \text {, } \\
\text { narcotráfico }(-1) \text {, } \\
\text { drogas }(-1) \text {, } \\
\text { trabajo ilegal }(-1) \text {, } \\
\text { mafias }(-1)\end{array}$ & -6 \\
\hline m6. Aída & $\begin{array}{l}\text { Oswaldo Witalco- } \\
\text { che (Machu Pichu) }\end{array}$ & $\begin{array}{l}\text { Gastronomía }(+1), \\
\text { felicidad/humor }(+1), \\
\text { inmigración }(0), \\
\text { pobreza }(-1), \\
\text { precariedad }(-1), \\
\text { trabajo ilegal }(-1)\end{array}$ & -1 \\
\hline
\end{tabular}

Fuente: Elaboración propia. 


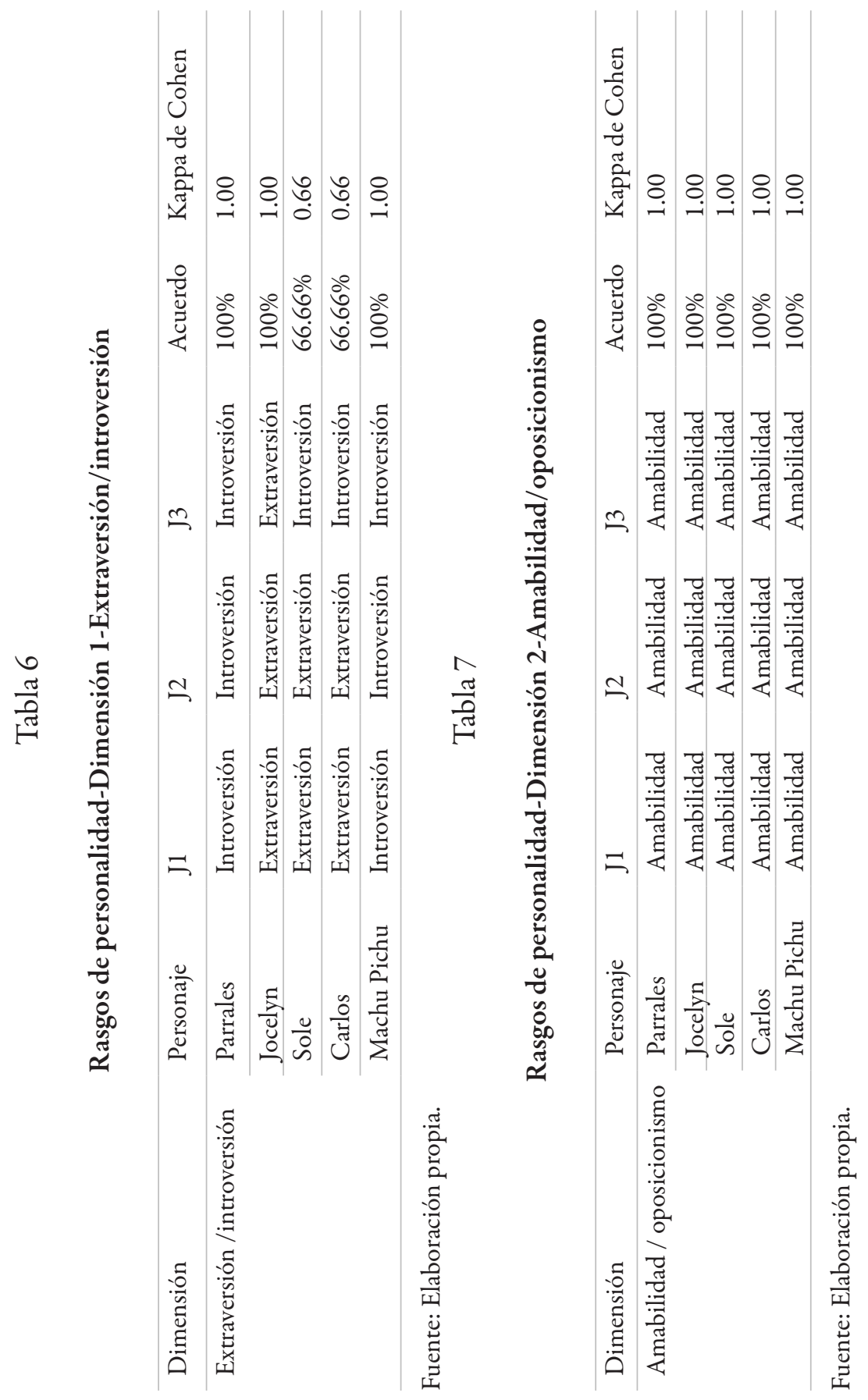


Luis M. Romero-Rodríguez, Patricia de-Casas-Moreno, Pablo Maraver-López y M. Amor Pérez-Rodríguez. Representaciones y estereotipos latinoamericanos en las series españolas de prime time (2014-2017)

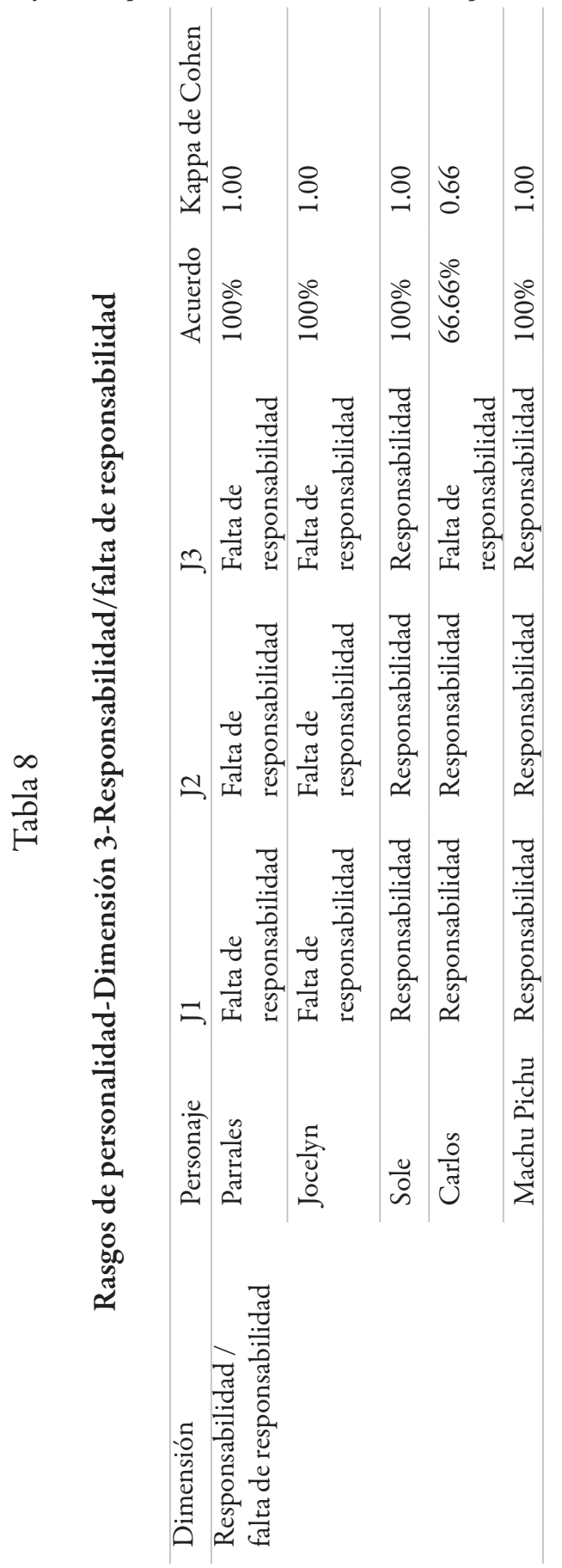

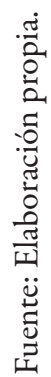




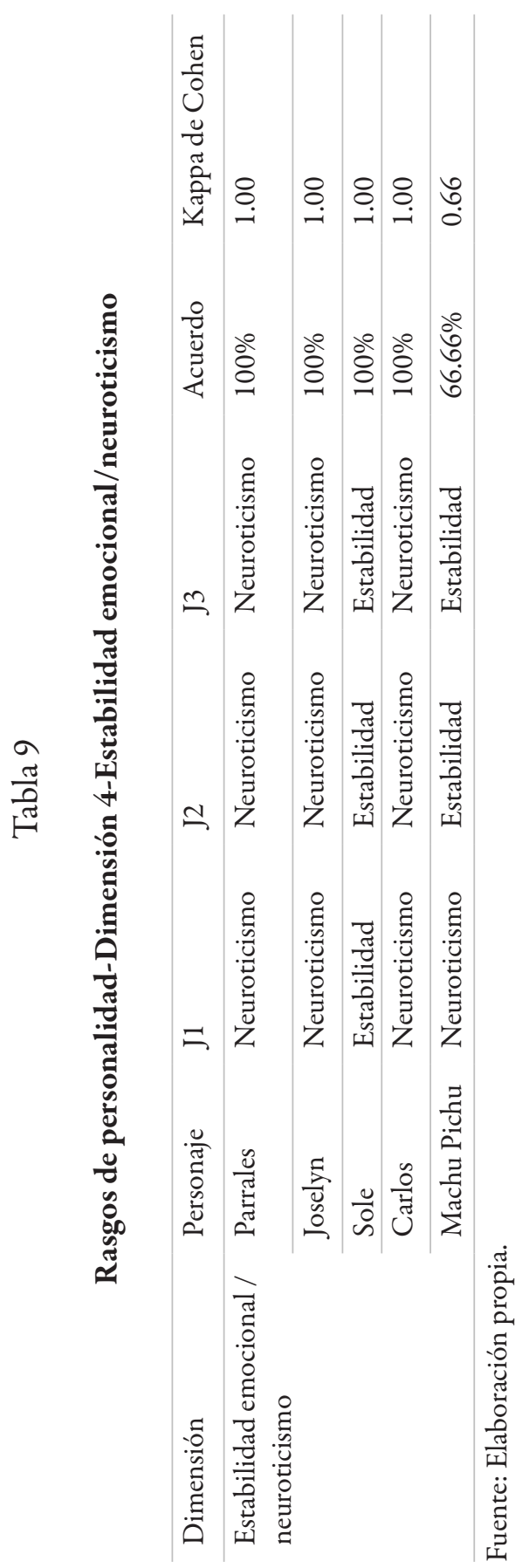


Luis M. Romero-Rodríguez, Patricia de-Casas-Moreno, Pablo Maraver-López y M. Amor Pérez-Rodríguez. Representaciones y estereotipos latinoamericanos en las series españolas de prime time (2014-2017)

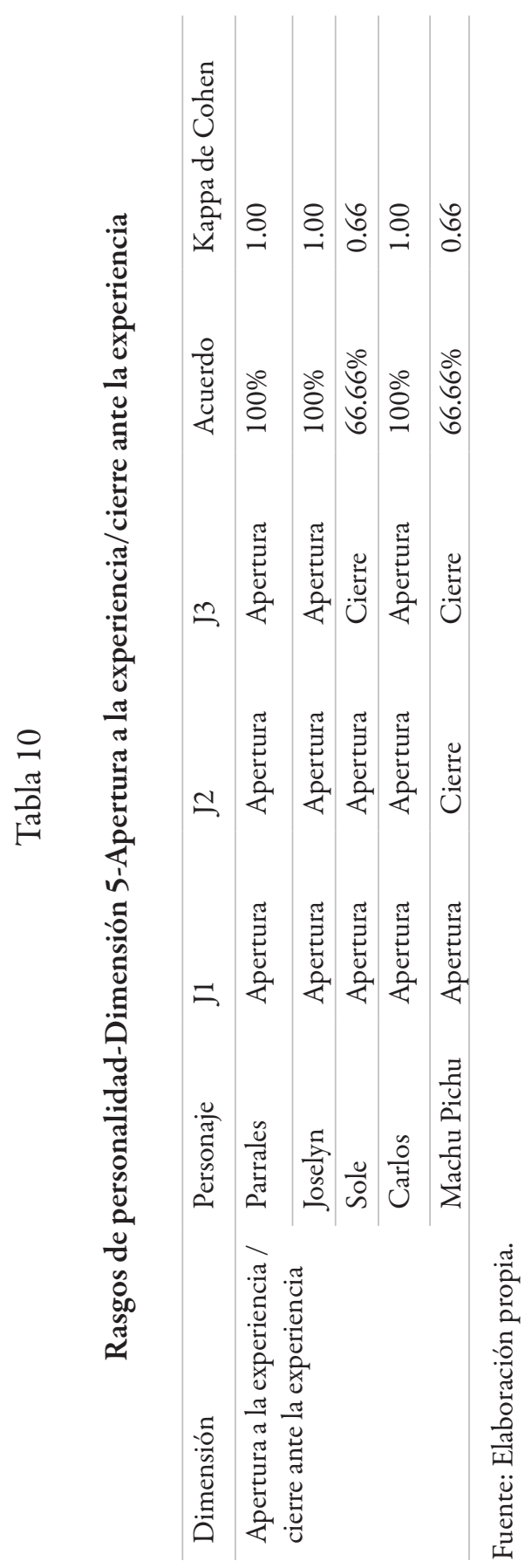


Luis M. Romero-Rodríguez. Profesor visitante del ESAI Business School de la Universidad Espíritu Santo (Ecuador) y docente nivel III de la Universidad Internacional de La Rioja (España), profesor invitado de la Universidad Internacional de Andalucía. Principal línea de investigación: análisis de la calidad de los medios de comunicación y las representaciones y estereotipos de grupos minoritarios en estos. Publicaciones recientes: de-Casas Moreno, P., Caldeiro-Pedreira, M. C. y Romero-Rodríguez, L. M., "La televisión como espejo de la realidad del 'bullying'. Percepciones de los adolescentes sobre el programa 'Proyecto Bullying', en Aula Abierta, vol. 47, núm. 2, España (2018); de-Casas-Moreno, P., Tejedor-Calvo, S. y Romero-Rodríguez, L. M., "Micronarrativas en Instagram: análisis del storytelling autobiográfico y de la proyección de identidades de los universitarios del ámbito de la comunicación”, en Prisma Social, núm. 20, España (2018); Torres-Toukoumidis, Á., Romero-Rodríguez, L. M., Pérez-Rodríguez, M. A. y Björk, S., "Modelo teórico integrado de gamificación en ambientes e-learning (E-Miga)", en Revista Complutense de Educación, vol. 2, núm. 1, España (2018).

Patricia de-Casas-Moreno. Profesora de la Universidad Antonio de Nebrija. Doctora en Comunicación en la rama de Alfabetización Mediática por la Universidad de Huelva. Principal línea de investigación: calidad de los medios de comunicación, los estereotipos, el lenguaje informativo y los hábitos de la audiencia como punto de partida de propuestas educativas para un mejor consumo por parte de la sociedad. Publicaciones recientes: deCasas Moreno, P., Caldeiro-Pedreira, M. C. y Romero-Rodríguez, L. M., "La televisión como espejo de la realidad del 'bullying. Percepciones de los adolescentes sobre el programa 'Proyecto Bullying', en Aula Abierta, vol. 47, núm. 2, España (2018); Rodrigo-Cano, D., de-Casas-Moreno, P. y Aguaded. I., "El rol del docente universitario y su implicación ante las humanidades digitales", en Index.Comunicación (aceptado) (2018); de-Casas-Moreno, P., Tejedor-Calvo, S. y Romero-Rodríguez, L. M., "Micronarrativas en Instagram: análisis del storytelling autobiográfico y de la proyección de identidades de los universitarios del ámbito de la comunicación", en Prisma Social, núm. 20, España (2018).

Pablo Maraver-López. Doctor en Ciencias de la Educación por la Universidad de Huelva. Personal investigador en el Programa de Formación de Profesorado Universitario (FPU) del Ministerio de Educación. Miembro del Grupo de Investigación "Ágora” (HUM 648) de la Universidad de Huelva. Principal línea de investigación: análisis de las interacciones producidas 
en contextos virtuales de aprendizaje. Publicaciones recientes: Castro, A., García-Ruiz, R., Maraver-López, P., "Impacto del practicum en las creencias de los maestros en formación sobre la relación familia-escuela”, en Revista Brasileira de Educação, núm. 23, Brasil (2018); Caldeiro-Pedreira, M. C., Maraver-López, P. y Marín-Gutiérrez, I., "Competencia mediática en la etapa infantil en España”, en Magis, Revista Internacional de Investigación en Educación, vol. 10, núm. 20, Colombia (2017); Maraver-López, Pablo, Caldeiro-Pedreira, Mari-Carmen y Pérez-Lisboa, S., "Percepción de la competencia mediática y la formación en maestros chilenos”, en Universitas, Revista de Ciencias Sociales y Humanas de la Universidad Politécnica Salesiana del Ecuador XV, núm. 27, Ecuador (2017).

M. Amor Pérez-Rodríguez. Profesora titular de la Universidad de Huelva. Principal línea de investigación: educomunicación. Publicaciones recientes: Pérez-Rodríguez, M. A. y Delgado-Ponce, Á., "Medios móviles emergentes en la enseñanza de lenguas”, en Prisma Social, núm. 20, España (2018); Bonilla-Del-Río, M., García-Ruiz, R. y Pérez-Rodríguez, M. A., "La educomunicación como reto para la educación inclusiva", en Edmetic. Revista de Educación mediática y TIC, vol. 7, núm. 1, España (2018); Torres-Toukoumidis, Á., Romero-Rodríguez, L. M. y Pérez-Rodríguez, M. A., Ludificación y sus posibilidades en el entorno de blended learning: revisión documental", en RIED. Revista Iberoamericana de Educación a Distancia, vol. 21, núm. 1, España (2018).

Recepción: 5 de noviembre de 2017.

Aprobación: 23 de abril de 2018. 
